\title{
Productivity shocks, monetary shocks, and the short- and long-run dynamics of exchange rates and relative prices
}

\author{
Michael Bergman \\ Lund University, S-220 07 Lund, Sweden \\ Yin-Wong Cheung \\ University of California, Santa Cruz, CA 95064, USA \\ Kon S. Lai \\ California State University, Los Angeles, CA 90032, USA
}

Revised, June 2000

\begin{abstract}
This study evaluates the individual roles of monetary and productivity shocks in real exchange rate fluctuations under the current float. Using a cointegration model of exchange rates and relative prices, the innovations are decomposed into transitory and common-trend parts. Both transitory and common-trend innovations are found to explain a significant portion of real exchange rate fluctuations, albeit their relative importance can vary across major currencies. Further analysis suggests that commontrend innovations are ascribed mostly to productivity shocks, whereas transitory innovations are governed by monetary shocks. The allowance for productivity shocks, however, appears insufficient to fully explain the high persistence of real exchange rates. (JEL F31, F41)
\end{abstract}

Key Words: Real exchange rate; real shock; monetary shock; transitory component; common trend

Please address all correspondence to:

Yin-Wong Cheung

Department of Economics

University of California

Santa Cruz, CA 95064

Tel: (831) 459-4247

E-mail: cheung@cats.ucsc.edu 


\section{Introduction}

Although international economists have commonly recognized the existence of large, persistent deviations from purchasing power parity (PPP) during the current float, identifying the contributing role of economic fundamentals in driving the deviations remains an unsettled empirical issue. The PPP theory, which serves as a key building block for many monetary models of exchange rate determination, suggests a long-run equilibrium relationship between exchange rates and relative national price levels. The analytical simplicity of the PPP relationship, as Lothian (1997) observes, may have contributed to its popular use. The PPP theory can be viewed as the open-economy extension of the quantity theory of money, and it posits that nominal disturbances have no permanent impact on the real exchange rate. Real disturbances exist but are not significant enough to preclude long-run reversion of the real exchange rate.

Early studies of the current float experience generally report evidence of a unit root in the real exchange rate (see Froot and Rogoff (1995) for an excellent survey), implying that permanent shocks are the predominant source of real exchange rate movements and that theoretical or empirical modeling of the underlying determinants of PPP deviations should focus primarily on real factors. An increasing number of recent studies, however, revive the empirical support for PPP reversion and find no unit root in real exchange rates during the recent float (Frankel and Rose, 1996; Oh, 1996; Papell, 1997; Wu, 1996; Cheung and Lai, 1998; Taylor and Sarno, 1998; Culver and Papell, 1999). These findings of parity reversion suggest that economic models emphasizing real factors as the principal determinants of real exchange rates will seriously understate the importance of monetory shocks. On the other hand, the stationarity findings should not deny the relevance of real shocks entirely. Real shocks may influence the stationary component and contribute to the observed persistence in real exchange rates. Indeed, the empirical rate of PPP reversion seems too sluggish to be explained by purely nominal shocks — referred to as the PPP puzzle (Rogoff, 1996).

Several studies have assessed the contribution of monetary shocks to dollar-based real exchange rates using the vector autoregression approach. Clarida and Gali (1994) and Eichenbaum and Evans (1995) analyze real exchange rate dynamics — including quarterly real rates of British pound, German 
mark and Japanese yen — during the current float, while Rogers (1999) examines over 100 years of annual data on real British pound rates. Although the contribution estimates have been mixed and the relative importance of monetary and real influences on real exchange rates is still in dispute, many models of exchange rate determination focus on monetary shocks exclusively (Beaudry and Devereux, 1995; Obstfeld and Rogoff, 1995; Alvarez and Atkeson, 1997; Chari, et al., 1998).

Canzoneri, et al. (1999) study a panel of 13 OECD countries and report that relative prices between traded and non-traded goods are cointegrated with relative labor productivity. In analyzing a long historical series of the real pound/dollar rate, Engel (2000) affirms a significant role of real shocks in real exchange rates and notes that standard unit root tests cannot conclusively rule out the presence of a permanent component when the transitory component is much more volatile. Kuo and Mikkola (1999) examine similar data on the real pound/dollar rate and estimate the relative likelihood of stationarity as opposed to nonstationarity. Based on simulated empirical distributions, the real exchange rate seems more likely to come from a stationary process than from a nonstationary one. Engel and Kim (1999) recognize the presence of nonstationarity in the real pound/dollar rate and decompose its dynamics into transitory and permanent components using a univariate Kalman filter model. These authors observe that while the transitory component is driven by monetary factors, the permanent component is cointegrated with relative per capita real output. Their findings are instructive: the stationary (transitory) and nonstationary (permanent) components of the real exchange rate are linked to macroeconomic variables in different ways. The results support an integrated model of PPP deviations in which both monetary and real factors are relevant.

In this study, we explore an alternative perspective on the individual roles of monetary shocks and productivity shocks in real exchange rate fluctuations under a framework of stationary real exchange rates. Instead of studying univariate series of real exchange rates, the joint behavior of exchange rates and relative prices is examined using a vector error correction (VEC) model. Even if exchange rates and relative prices will converge to an equilibrium relationship over the long run, the two variables can exhibit rather different short-term behavior. Hence, the bivariate VEC model may capture short-term PPP deviations with richer dynamics than an univariate model of real exchange rates. The allowance for 
richer short-term dynamics may help identify better the contribution of transitory disturbances.

The VEC analysis also permits us to address directly the question of whether exchange rates and relative prices are cointegrated. In finding a stationary relationship between exchange rates and relative prices, the results from this study retain the consistency with those other recent findings of stationarity in real exchange rates. When exchange rates are cointegrated with relative prices, their joint dynamics can be broken into a common-trend component and a transitory component, allowing us to identify the possibly different sources of disturbances that are driving the long-term comovements and short-term deviations between exchange rates and relative prices. The decomposition analysis is derived directly from the stochastic properties of the different components, and no specific structural relationships between the cointegrated system and the macroeconomic factors are imposed. Without imposing any a priori structural restrictions, we let the data reveal and determine the potential linkage between the innovations driving the cointegrated system and the relevant macroeconomic changes.

Innovations to the common-trend component are permanent shocks to the exchange rate and the relative price, but the long-run responses of these variables will offset one another, leaving no permanent effects on the real exchange rate. The real exchange rate thus maintains its stationarity, and permanent and transitory shocks are alike in producing merely temporary effects on it. It should be noted that common-trend innovations cannot be identified in a univariate time series model of real exchange rates. Under the univariate framework, common-trend and transitory innovations cannot be separately extracted from real exchange rate series. This underscores the special merit of our bivariate modeling approach.

This study shows that common-trend innovations are attributed mainly to productivity changes, whereas transitory innovations are driven mostly by monetary changes. It follows that real shocks can still play a significant role in real exchange rate fluctuations, without the real exchange rate being nonstationary. The growing findings of stationarity reported in the recent studies are thus reconcilable with the other emerging findings supporting the significance of productivity shocks for the real exchange rate. Indeed, the empirical support for the relevance of productivity shocks is further strengthened by showing the robustness of the findings with respect to the stationarity property of the real exchange rate. 


\section{The analytical background}

The intellectual origins of the PPP proposition can be traced back to the writings of Wheatley (1803, 1807) and Ricardo $(1811,1821)$. As discussed by Frenkel (1978), these originators view PPP as an extension of the quantity theory of money to the open economy. Exchange rates like prices reflect the underlying monetary conditions in the countries concerned. The revived interest in PPP owes much to Cassel's $(1916,1921,1922)$ strong advocacy of its practical use. There are many variants of monetary models of PPP deviations. For illustration we follow Niehans's (1984) excellent simple exposition, which captures the central elements of the monetary perspective.

Consider an empirical PPP relationship in terms of relative prices of tradables:

$$
E=\zeta P_{T} / P_{T}^{*}
$$

where $E$ is the dollar price of foreign currency, $\zeta$ is a variable capturing short-term deviations from PPP, $P_{T}$ is the US traded goods price, and $P_{T}^{*}$ is the foreign traded goods price. The short-term dynamics of $\zeta$ can be influenced by monetary factors such as relative interest rates (Dornbusch, 1976). In each country the demand for money $\left(M_{D}\right)$ is considered to be a function of the traded goods price and the nontraded goods price $\left(P_{N}\right)$ :

$$
\begin{aligned}
& M_{D}=M_{D}\left(P_{T}, P_{N}\right) \\
& M_{D}^{*}=M_{D}^{*}\left(P_{T}^{*}, P_{N}^{*}\right)
\end{aligned}
$$

where an asterisk indicates the relevant variables for the foreign country. Interest rates may be included also in the money demand functions without altering the main structure of the model. In monetary equilibrium, the money demand equals the money supply. In the absence of money illusion, the money demand function is homogeneous of degree one in prices and we have

$$
\begin{aligned}
& M_{S}=P m_{D}\left(\tau_{T}, \tau_{N}\right) \\
& M_{S}^{*}=P^{*} m_{D}^{*}\left(\tau_{T}^{*}, \tau_{N}^{*}\right)
\end{aligned}
$$

where $M_{S}$ and $M_{S}^{*}$ are, respectively, the domestic and foreign money supply; $\tau_{T}=P_{T} / P ; \tau_{N}=P_{N} / P ; \tau_{T}^{*}=$ $P_{T}^{*} / P^{*} ; \tau_{N}^{*}=P_{N}^{*} / P^{*} ; P=g\left(P_{T}, P_{N}\right)$ is the domestic overall price index; and $P^{*}=g^{*}\left(P_{T}^{*}, P_{N}^{*}\right)$ is the foreign overall price index. The price ratios, given by $\tau_{T} \tau_{N}, \tau_{T}^{*}$ and $\tau_{N}^{*}$, depend on the output market conditions. 
Using (4) and (5), the PPP relationship in (1) can be rewritten in terms of general price levels:

$$
E=\zeta \phi P / P^{*}
$$

with

$$
\begin{aligned}
& E=\zeta \phi\left[\lambda M_{S} / M_{S}^{*}\right] \\
& P / P^{*}=\lambda M_{S} / M_{S}^{*}
\end{aligned}
$$

where $\phi=\tau_{T} / \tau_{T}^{*}$ and $\lambda=m_{D}^{*}\left(\tau_{T}^{*}, \tau_{N}^{*}\right) / m_{D}\left(\tau_{T}, \tau_{N}\right)$. This system highlights the link between the exchange rate, relative price levels and monetary factors. The real exchange rate is given by $Q=E P^{*} / P$.

Empirically, both the exchange rate and relative price levels are found to be nonstationary variables, and whether the PPP relationship holds in the long run is governed by the cointegration property between $E$ and $P / P^{*}$. Note that the exchange rate and the relative price are driven by some common factors.

Deviations from PPP (i.e., departures between $E$ and $P / P^{*}$ ) are determined by $\zeta$ and $\phi$. While $\zeta$ captures PPP deviations that are monetary in origin, $\phi$ is driven by real factors affecting output market conditions. If real disturbances exert long-lasting effects on either $\tau_{T}$ or $\tau_{T}^{*}$ through their influences on relative prices of tradables, the deviations from PPP can be permanent and the real exchange rate will then be nonstationary. Some theoretical models in the PPP literature recognize explicitly the possibility of permanent shifts in $\phi$, typically as a result of such real changes as productivity shocks and differentials in productivity growth between countries (à la the Balassa-Samuelson hypothesis). It should be noted that although permanent effects are often ascribed to real shocks and temporary effects to nominal shocks as a useful first approximation, such a dichotomous role ascription seems unnecessarily stringent and may not be totally accurate. In particular, real disturbances can produce purely temporary effects (Evans and Lothian, 1993). Hence, the actual impact of real and monetary shocks is largely an empirical issue.

Long-term comovements between $E$ and $P / P^{*}$ will exist when PPP deviations are stationary. In this situation the comovements are said to be governed by a common stochastic trend. As indicated in (7) and (8), the common trend is driven by $\lambda$ and $M_{S} / M_{S}^{*}$. All else equal, an increase in the domestic money supply, for instance, will result in proportional long-run movements in $E$ and $P / P^{*}$. In addition, changes in real factors such as productivity changes may contribute to common-trend movements through their 
influences on $\lambda$ if they produce systematic effects on relative prices of traded goods. Niehans (1984) points out that the relationship between exchange rates and relative prices comes about because they are endogenous variables jointly dependent on the money supply. A similar point has been made by Angell (1926) and Haberler (1936). Angell (1926; p.447) notes that "both prices and exchange movements were common products of a common antecedent condition." Hence, the notion of the common trend naturally lends itself to analyzing the dynamics of exchange rates and relative prices as a bivariate system.

It should be emphasized that although the monetary model of PPP deviations highlights the role of monetary factors, it also recognizes the potentially significant influence of real factors. As illustrated above, the short-term deviations and long-term comovements between the exchange rate and the relative price can be affected by both real and monetary factors, albeit through possibly different channels.

\section{The statistical framework}

To study the short- and long-run behavior of the real exchange rate, a bivariate system comprising the log of the nominal exchange rate $\left(e_{t}\right)$ and the log of relative price levels $\left(p_{t}\right)$ is considered. Since $e_{t}$ and $p_{t}$ are nonstationary — and the real exchange rate (measured by $e_{t}-p_{t}$ ) is stationary under the long-run PPP condition - it seems natural to model the dynamics of the system as the VEC model:

$$
\Delta X_{t}=\mu+\sum_{j=1}^{p-1} \Gamma_{j} \Delta X_{t-j}-\Pi X_{t-p}+\varepsilon_{t}
$$

where $X_{t}=\left[\begin{array}{ll}e_{t} & p_{t}\end{array}\right]^{\prime},-\Pi=\alpha \beta^{\prime}, \operatorname{rank}(\Pi)=1, \alpha=\left[\begin{array}{ll}\alpha_{1} & \alpha_{2}\end{array}\right]^{\prime}$ contains adjustment coefficients, $\beta$ is the cointegration vector, and $\varepsilon_{t}$ are i.i.d. with mean zero and covariance matrix, $\Omega$. To incorporate the longrun PPP condition, the cointegration vector equals $\left[\begin{array}{ll}1 & -1\end{array}\right]^{\prime}$ such that the real exchange rate, given by $\beta^{\prime} X_{t}$, is stationary and $\left|\alpha_{1}\right|+\left|\alpha_{2}\right| \neq 0$. The last condition, $\left|\alpha_{1}\right|+\left|\alpha_{2}\right| \neq 0$, can be verified as a test for cointegration. The system innovations can be decomposed into transitory and permanent parts. If no cointegration exists, permanent innovations to $e_{t}$ and $p_{t}$ will have long-run effects on the real exchange rate. It cointegration does exist, $e_{t}$ and $p_{t}$ will share a common permanent component, and the effects of permanent innovations to $e_{t}$ and $p_{t}$ will offset one another, yielding only temporary effects on the real exchange rate. The common permanent component has been referred to as the common trend. 
Since $\Delta X_{t}$ is stationary, the Wold decomposition theorem implies the presence of a vector moving average (VMA) representation:

$$
\Delta X_{t}=\delta+C(L) \varepsilon_{t}
$$

where $L$ is the lag operator, $C(L)=I_{2}+\sum_{k=1}^{\infty} C_{k} L^{k}, I_{2}$ is a $2 \times 2$ identity matrix, $\operatorname{rank}[C(1)]=1, \beta^{\prime} C(1)=$ $0, \delta=C(1) \mu$, and $\beta^{\prime} \delta=0$. Equations (9) and (10) allow us to study the short- and long-run interactions between the exchange rate and the relative price as well as the impulse responses to variable-specific shocks (Lütkepohl and Reimers, 1992; Pesaran and Shin, 1998).

The common-trend (CT) representation of a cointegrated system, on the other hand, can be used to analyze the impact of shocks of a specific nature: shocks to the transitory component as opposed to shocks to the CT component. The CT representation for the VEC model is (Stock and Watson, 1988):

$$
X_{t}=\mu_{0}+\Phi \eta_{t}+Q^{*}(L) w_{t}
$$

where $\eta_{t}=\rho+\eta_{t-1}+\varphi_{t} ; Q^{*}(L)$ is a stationary lag polynomial; and $w_{t}=\left[\begin{array}{ll}\varphi_{t} & \psi_{t}\end{array}\right]^{\prime}$ with $\varphi_{t}$ being the shock to the CT component and $\psi_{t}$ being the innovation to the transitory component ( $\varphi_{t}$ and $\psi_{t}$, sometimes referred to as structural innovations, are orthogonal with covariance matrix, $I_{2}$ ). Equivalently, we have

$$
X_{t}=\mu_{0}+\Phi\left\{\eta_{0}+\rho t+\sum_{i=1}^{t} \varphi_{i}\right\}+Q^{*}(L) w_{t} .
$$

The common stochastic trend, $\eta_{t}$, determines the trending behavior of the exchange rate and the relative price through the loading matrix, $\Phi$. The transitory dynamics of the system are governed by $Q^{*}(L) w_{t}$. In addition, since cointegration implies that $\beta^{\prime} \Phi=0$, the dynamics of the real exchange rate are given $\beta^{\prime} \mu_{0}$ $+\beta^{\prime} Q^{*}(L) w_{t}$. Equation (11) can be expressed alternatively as

$$
\Delta X_{t}=\delta+Q(L) v_{t} \equiv \delta+C(L) F^{-1} w_{t}
$$

where $Q(L)=Q(1)+(1-L) Q^{*}(L)$. The CT representation is thus linked to the VMA representation via the transformation matrix, $F$, such that $w_{t}=F \varepsilon_{t}$. If $F=\left[\begin{array}{ll}F_{1} & F_{2}\end{array}\right]^{\prime}$ can be explicitly determined, individual shocks to the CT and transitory components of the system can also be constructed. It can be shown (see appendix A) that for the cointegrated system under study, we have

$$
\begin{aligned}
& \varphi_{t}=\operatorname{det}(B(1))^{-1}\left[\begin{array}{ll}
-\alpha_{2} & \alpha_{1}
\end{array}\right] \varepsilon_{t}=F_{1} \varepsilon_{t} \\
& \psi_{t}=\left(\alpha^{\prime} \Omega^{-1} \alpha\right)^{-1 / 2} \alpha^{\prime} \Omega^{-1} \varepsilon_{t}=F_{2} \varepsilon_{t}
\end{aligned}
$$

where $B(1)$ is defined in the appendix. The transitory innovation, $\Psi_{t}$, generates solely temporary effects 
on the exchange rate and the relative price, hence no permanent effects on the real exchange rate. The CT innovation, $\varphi_{t}$, generates long-lasting effects on the exchange rate and the relative price, but these effects will cancel out one another over the long run, leaving no permanent effects on the real exchange rate. The impulse responses of the exchange rate and the relative price to the individual innovations are

given by $C(L) F^{-1}$, and those of the real exchange rate are given by $\beta^{\prime} C(L) F^{-1}$. However, the construction of these shocks does not tell us whether these shocks are related to, e.g., productivity and monetary factors. In our subsequent analysis the relevant economic factors attributable to these shocks will be determined using time series analysis, and no specific structural relationships will be imposed a priori.

\section{Different effects of transitory and common-trend innovations}

The dynamic behavior of exchange rates and relative prices under the current float are examined. The data consist of monthly series of consumer price indices and dollar-based exchange rates over the sample period from April 1973 through December 1998. Three major currencies — German mark (DM), Japanese yen (JY) and British pound (BP) — are studied. The data sources are described in appendix B.

Before performing the analysis of transitory and CT innovations, the cointegration property between exchange rates and relative prices is first verified. The VEC model in (9) is estimated and its lag specification is selected based on three information criteria as well as diagnostic checking of the residuals. We use three lags for Germany, four lags for Japan and two lags for the United Kingdom. The coefficient estimates of the VEC model will later be used to construct the transitory and common-trend components and compute impulse responses. Since cointegration between $e_{t}$ and $p_{t}$ requires that at least one of the error-correction coefficients is non-zero (i.e., $\left|\alpha_{1}\right|+\left|\alpha_{2}\right| \neq 0$ ), estimates of $\alpha_{1}$ and $\alpha_{2}$ are reported in Table 1. A Wald test for the null hypothesis of $\left|\alpha_{1}\right|+\left|\alpha_{2}\right|=0$ against the non-zero-sum alternative is conducted. In all cases the null of $\left|\alpha_{1}\right|+\left|\alpha_{2}\right|=0$ can be rejected at the 5 percent level of significance or better, supporting the presence of a stationary relationship between $e_{t}$ and $p_{t}$. Since the PPP relationship is stationary, shocks to either $e_{t}$ or $p_{t}$ will have no long-run effects on the real exchange rate. Some shocks can have permanent effects on the exchange rate and the relative price, but in the long 
run these effects offset one another because of their opposite signs (the cointegration vector is $\left[\begin{array}{ll}1 & -1\end{array}\right]^{\prime}$ ). Such common permanent effects are characterized by a common stochastic trend, which describes the long-run trending behavior of both the exchange rate and the relative price.

Since the bivariate system for $\left[\begin{array}{ll}e_{t} & p_{t}\end{array}\right]$ is found to be cointegrated, its system dynamics can be decomposed into a transitory component and a CT component, as discussed in section 3 . Figure 1 displays the estimated CT components corresponding to the cases of Germany, Japan and the United Kingdom. These common trends (indicated by solid lines) capture the trending dynamics shared by the exchange rate and the relative price (indicated by broken lines in individual graphs). In particular, the common trends can track the relative price movements very closely in all the cases. Results reported later in this paper reveal that the common trends are linked mostly to productivity changes.

We next examine how the system dynamics will react to the different innovations to the transitory and CT components. Figure 2 contains the impulse responses of exchange rates, relative prices and real exchange rates to a one-standard-deviation transitory innovation. The 95 percent confidence bands (as broken lines) of the impulse responses are also included. As expected, transitory innovations have only temporary effects on exchange rates, relative prices as well as real exchange rates. In all cases the response of the exchange rate is much stronger than that of the relative price. This may reflect the property that price adjustment is often quite sluggish, while the exchange rate reacts quickly to shocks.

Figure 3 displays the impulse responses of the various variables to a one-standard-deviation CT innovation, along with their 95 percent confidence bands. We notice that although the CT innovation has very long-lived effects on both the exchange rate and the relative price, these effects tend to offset one another over time. Consequently, the CT innovation produces no permanent effects on the real exchange rate. Again, the response of the exchange rate is found to be much larger in magnitude than that of the relative price in every case.

Variance decomposition analysis is next conducted. The forecast error variance for the exchange rate, the relative price and the real exchange rate is broken into portions explained by the two types of innovations. The decomposition reveals the relative importance of transitory and CT innovations in explaining the fluctuations of the economic variables over different horizons (see figures 4 and 5). 
Table 2 reports the forecast error decomposition estimates for the exchange rate (confidence interval estimates have been plotted in the graphs and are not tabulated to conserve space). At the short three-month horizon, transitory innovations are more significant than CT innovations in explaining the exchange rate fluctuations for DM, but the reverse is true for JY and BP. The relative importance of CT innovations is particularly prominent in the case of Japan. Over horizons of six months or more, CT innovations consistently account for most of the exchange rate fluctuations. Indeed, the relative importance of CT innovations grows steadily as the horizon lengthens. At the four-year horizon, for example, CT innovations can explain 65 to 88 percent of the exchange rate fluctuations for different countries. At the eight-year horizon, they account for 70 to 90 percent of the fluctuations.

The decomposition estimates for the relative price are given in Table 3. Again, different results across countries can be seen at short horizons. For the United Kingdom, transitory innovations produce a larger part of the relative price fluctuations than CT innovations over horizons of six months or less. For Japan, transitory innovations contribute to most of the relative price variation over the two-year horizon or shorter. For Germany, CT innovations, not transitory innovations, account for most of the relative price variation even over short horizons. Despite the short-horizon results, the fraction explained by CT innovations rises and the fraction ascribed to transitory innovations becomes increasingly unimportant in all the cases as the horizon extends. At the four-year (eight-year) horizon, CT innovations generate 67 to 89 percent (87 to 95 percent) of the relative price fluctuations for different countries.

Table 4 contains the decomposition estimates for the real exchange rate. Unlike the exchange rate and the relative price, for which CT innovations have burgeoning influences and always dominate at long horizons, no uniform results are found across countries for the real exchange rate. This reflects the offsetting effects of CT innovations on the exchange rate and the relative price. The contribution of CT innovations remains relatively unchanged with longer horizons for both real JY and BP rates. For the real JY rate, transitory and CT innovations explain about 29 and 71 percent of the real exchange rate fluctuations, respectively. For the real BP rate, the respective fractions attributable to transitory and CT innovations are estimated to be 67 and 33 percent. For the real DM rate, the importance of CT innovations rises and that of transitory innovations falls steadily as the horizon lengthens. Transitory 
innovations, nonetheless, still explain more than half of the real exchange rate variation.

In addition to gauging the relative contributions of $\mathrm{CT}$ and transitory innovations to real

exchange rate variability, we also analyze the persistence of real exchange rate adjustment with respect to the different innovations. According to our half-life persistence estimates, real exchange rate adjustment to CT innovations is generally more persistent than that to transitory innovations, but the difference seems not substantial. For the real DM rate, the estimated half-lives are 3.8 years in the case of CT innovations and 2.9 years in the case of transitory innovations. For the real JY rate, the estimated halflives are 5.0 years in the case of CT innovations and 4.5 years in the case of transitory innovations. For the real BP rate, the estimated half-lives are 2.8 years in the case of CT innovations and 2.7 years in the case of transitory innovations. These half-life estimates are comparable with the usual estimates of 3 to 5 years reported in the PPP literature.

The above analysis has investigated the short- and long-horizon adjustment dynamics of the real exchange rate in a bivariate model of the exchange rate and the relative price. Our main conclusion is that both $\mathrm{CT}$ and transitory innovations significantly contribute to the variability of the real exchange rate and its persistence, albeit with differing relative importance across countries. It follows that empirical modeling of real exchange rate dynamics should recognize the individual significance of both CT and transitory innovations. This shows the merit of our bivariate analysis when compared with univariate analysis of the real exchange rate. The latter does not allow us to identify CT innovations separately.

\section{Macroeconomic sources of innovations}

While both CT and transitory innovations are shown to be important to the variability and persistence of the real exchange rate, no attempt has yet been given to study the economic sources of the two types of innovations. It is this issue we now turn to. As motivated by the analytical model in section 2, we explore whether the CT and transitory innovations can be linked in different ways to changes in macroeconomic variables: productivity differentials $(P R)$, relative money supply $(M S)$ and interest rate differentials $(I R)$. Productivity is measured as industrial production divided by labor employment (see 
appendix B for data sources).

Granger causality tests are applied to examine whether the CT and transitory innovations are related to macroeconomic changes. As the macroeconomic series typically are nonstationary, we set up VEC models. Since both CT and transitory innovations are stationary series, accumulated innovations are considered. In the $\mathrm{CT}$ case, the accumulated $\mathrm{CT}$ innovation gives the common trend, which drives the nonstationarity of the exchange rate and the relative price. Consider the following VEC model:

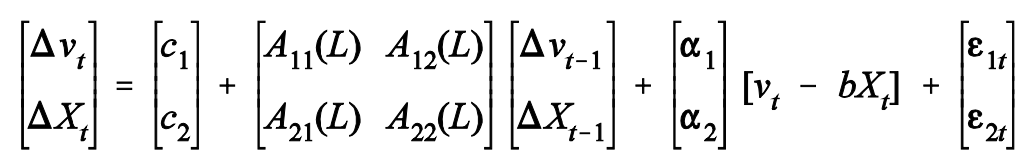

where $v_{t}$ is the accumulated CT or transitory innovation (i.e., $\Delta v_{t}=\varphi_{t}$ or $\left.\psi_{t}\right) ; X_{t}=\left[\begin{array}{lll}P R_{t} & M S_{t} & I R_{t}\end{array}\right]^{\prime}$ is a vector of macroeconomic variables; $c_{1}$ and $c_{2}$ are constant terms; $\alpha_{1}$ and $\alpha_{2}$ are the error correction coefficients; and $b$ is the normalized coefficient in the cointegration vector. Whether the macroeconomic variables in $X_{t}$ cause $v_{t}$ can be tested based on the statistical significance of $A_{12}(L)$ and $\alpha_{1}$. Under the null hypothesis that all the macroeconomic variables have no influences, $A_{12}(L)=0$ and $\alpha_{1}$ $=0$. Note that if we exclude the error correction term, the system (16) becomes a vector autoregression model in terms of the structural innovation $\left(\varphi_{t}\right.$ or $\left.\psi_{t}\right)$ and the changes in macroeconomic variables $\left(\Delta P R_{t}\right.$, $\Delta M S_{t}$ and $\left.\Delta I R_{t}\right)$

Table 5 summarizes the results from tests for causal effects of individual macroeconomic variables. Prior to performing the causality tests, Johansen's (1995) method is used to verify the cointegration property and estimate the cointegration vector. Significant evidence of cointegration is found in almost all the cases, except for the Japan case of the CT innovation. The cointegration results match exactly the reported significance of the error correction terms in different cases. Experimenting with various lag selection methods leads us to use five lags in the VEC model. Various lags have also been tried, and the statistical results are not sensitive to the lag length.

The p-values from standard Wald tests for Granger causality of individual macroeconomic variables are reported in Table 5. The cases of Germany and Japan yield rather similar results: CT innovations are linked to productivity and money supply changes, whereas transitory innovations are 
ascribable to interest rate and money supply changes. The U.K. case gives somewhat different results: CT innovations seem not directly linked to any of the macroeconomic variables, whereas transitory innovations are related mainly to interest rate changes. To be sure, CT innovations can still be linked to some of the macroeconomic variables indirectly via the error correction term, which is statistically significant. Further tests of cointegration between the CT component and individual macroeconomic variables point to the existence of a long-run relationship between the CT component and the productivity differential (though not the other macroeconomic variables) in the U.K. case.

Table 6 presents variance decomposition estimates, which quantify the relative contributions of the macroeconomic variables to the CT and transitory innovations. In general, a significant portion of the forecast error variance of either $\mathrm{CT}$ or transitory innovations can be attributed to past changes in macroeconomic factors. Among the three macroeconomic variables under study, productivity changes are most important in explaining the variance of CT innovations. Although CT innovations have been found to be linked to both productivity and money supply changes in the Germany and Japan cases, productivity changes dominate money supply changes in terms of the contribution to the variability of CT innovations. In these two cases, productivity changes can explain 50\% or more of the variance of CT innovations at long horizons, whereas monetary changes — including both money supply and interest rate changes - explain less than $13 \%$ of the innovation variance. In the U.K. case, productivity changes account for a small fraction (less than 14\%) of the innovation variance, but the fraction is still much larger than that explained by monetary changes (less than $3 \%$ ).

Interest rate changes are most important in explaining the variability of transitory innovations. This confirms the importance of interest rate differentials in driving transitory exchange rate dynamics, as stressed by Dornbusch-type monetary models. The portion of the innovation variance attributable to interest rate changes can range from $47 \%$ in the case of Japan to $64 \%$ in the case of Germany. Second to interest rate changes, money supply changes also contribute materially to the innovation variance in the Japan and U.K. cases. Interest rate and money supply changes together can explain up to $84 \%$ of the variance of transitory innovations in the Germany case, $77 \%$ in the Japan case and $81 \%$ in the U.K. case.

Since productivity changes represent real shocks and both money supply and interest rate 
changes represent monetary shocks, the findings here indicate that the CT component is driven mostly by real shocks and the transitory component is governed by monetary shocks. The results further support that real and monetary shocks can both contribute significantly to the real exchange rate dynamics, given that CT innovations as well as transitory innovations have earlier been shown to explain a considerable portion of the real exchange rate variability. Of course, the relative importance of real and monetary shocks can still vary across countries. According to the results reported earlier in Table 4, about $42 \%$ (for DM), $71 \%$ (for JY) and 33\% (for BP) of the variance of the real exchange rate can be attributed to CT innovations, whereas about 58\% (for DM), 29\% (for JY) and 67\% (for BP) of the variance of the real exchange rate can be ascribed to transitory innovations. Since CT innovations come mostly from real shocks and transitory innovations come primarily from monetary shocks, our findings suggest that real shocks are more important than monetary shocks in driving the real exchange rate dynamics in the case of Japan and that monetary shocks are more important than real shocks in driving the real exchange rate dynamics in the cases of DM and BP.

Some remarks concerning the PPP puzzle (Rogoff, 1996) discussed in the recent literature are in order. Although the enormous short-term volatility of the exchange rate suggests a likely important role of monetary shocks, the observed half-life persistence of the real exchange rate seems too high to be generated by monetary disturbances, even with price stickiness (see also Chari, et al, 1998). The middle ground is that the real exchange rate is buffeted by both real and monetary disturbances. PPP reversion may actually be rather fast subsequent to monetary shocks, and the high persistence in the real exchange rate is largely induced by real shocks. The findings here confirm the empirical relevance of both monetary and real shocks. The allowance for real shocks cannot resolve the PPP puzzle, nevertheless.

Based on the half-life estimates reported earlier, the persistence of the real exchange rate with respect to transitory innovations remains very high. Given that transitory innovations come primarily from monetary shocks and that they can produce such highly persistent real exchange rate dynamics, our findings still raise the basic question: How can the high persistence of the real exchange rate be generated by monetary shocks? In the DM and BP cases, indeed, monetary shocks are found to be the dominating source of innovations. The allowance for productivity shocks seem insufficient to fully 
account for the high persistence observed in the real exchange rate. In other words, the PPP puzzle cannot be resolved by identifying the relative importance of monetary and real shocks.

\section{Summary and conclusion}

The dynamic properties of the different innovations underlying the real exchange rate and their possible sources have been explored. Specifically, the study analyzes the significance of productivity, money supply and interest rate changes in driving the different dynamic components of the real exchange rate. In estimating a bivariate cointegration model of exchange rates and relative prices, the structural innovations are decomposed into transitory and common-trend innovations. Common-trend innovations are permanent shocks to the exchange rate and the relative price, but they generate no permanent effects on the real exchange rate. It is shown that both transitory and common-trend innovations can explain a significant portion of the real exchange rate fluctuations, albeit their relative importance may vary across currencies, with common-trend innovations being more important to the real Japanese yen rate and transitory innovations being more important to the real German mark and British pound rates.

Further analysis suggests that common-trend innovations are ascribed mostly to productivity changes, whereas transitory innovations are governed by monetary changes. Accordingly, the empirical significance of productivity shocks in real exchange rate dynamics is established without nonstationarity in real exchange rates. The findings here complement both the growing evidence of parity reversion in real exchange rates and the emerging evidence for the significance of productivity shocks reported in previous studies. Our analysis shows, however, that the allowance for the effects of productivity shocks on real exchange rate dynamics appears not enough to resolve the issue concerning the high persistence of PPP deviations. In particular, the very high persistence of real exchange rate adjustment associated with monetary shocks remains puzzling.

A possible interpretation of the findings is the missing-variable perspective. May some other macroeconomic changes not considered in this study be responsible for the high persistence of the real exchange rate? How significant is the potential role of microeconomic factors (e.g., the pricing- 
to-market behavior examined by Bergin and Feenstra, 1999) - typically ignored by macroeconomic models of PPP deviations — in contributing to the observed persistence? These are questions warranting further investigation in future research. 


\section{Appendix A: Identification for common-trend decomposition}

To determine $F$, we first derive $C(L)$ and then find the CT representation of the VMA model. The basic analysis is based on King, et al. (1990), Mellander, et al. (1992), and Bergman (1996). Following Campbell and Shiller (1988), let

$$
M=\left[\begin{array}{cc}
1 & 0 \\
1 & -1
\end{array}\right] .
$$

Also, let $\Gamma(L)=I_{2}-\sum_{j=1}^{p-1} \Gamma_{j}$. Premultiplying both sides of the VEC model in (9) yields

$$
M \Gamma(L) \Delta X_{t}=M \mu-M \Pi X_{t-p}+M \varepsilon_{t}
$$

Define a stationary variable $y_{t}=D_{\perp}(L) M X_{t}$, where $D_{\perp}$ is a diagonal matrix with its diagonal elements given by $D_{\perp}(L)_{11}=1-L$ and $D_{\perp}(\mathrm{L})_{22}=1$. This implies that $y_{t}=\left[(1-L) e_{t} e_{t}^{-} p_{t}\right]^{\prime}$. Accordingly, we have

$$
y_{t}=B^{-1}(L)\left\{M \mu+M \varepsilon_{t}\right\}
$$

with $B(L)=M\left\{\Gamma(L) M^{-1} D(L)+\alpha^{*} L^{p}\right\}$, where $\alpha^{*}=\left[\begin{array}{ll}\alpha_{1} & \alpha_{2}\end{array}\right]^{\prime}\left[\begin{array}{ll}0 & 1\end{array}\right]$ and $D(L)$ is a diagonal matrix with its diagonal elements given by $D(L)_{11}=1$ and $D(L)_{22}=1-L$. Since $\Delta X_{t}=M^{-1} D(L) y_{t}$, comparing this with equation (10) yields

$$
C(L)=M^{-1} D(L) B(L)^{-1} M .
$$

This relationship between estimates of $B(\mathrm{~L})$ and the moving average lag polynomial $C(\mathrm{~L})$ implies that

$$
C(1)=\frac{1}{\operatorname{det}(B(1))}\left[\begin{array}{ll}
B(1)_{22}-B(1)_{12} & B(1)_{12} \\
B(1)_{22}-B(1)_{12} & B(1)_{12}
\end{array}\right]
$$

Moreover, the adjustment coefficients are given by $\alpha_{1}=B(1)_{12}$ and $\alpha_{2}=B(1)_{12}-B(1)_{22}$.

We next derive the CT component of the system. Equation (10) can be expressed as

$$
\Delta X_{t}=\delta+C(1) \varepsilon_{t}+(1-L) C^{*}(L) \varepsilon_{t}
$$

by writing $C(L)$ as $C(1)+(1-L) C^{*}(L)$. Hence, assuming that $\varepsilon_{0}=0$, we have

$$
X_{t}=X_{0}+\delta t+C(1) \sum_{i=1}^{t} \varepsilon_{i}+C^{*}(L) \varepsilon_{t}
$$

Comparing this with equation (12) gives $\Phi \varphi_{t}=C(1) \varepsilon_{t}$. Since $\beta^{\prime} \Phi=0$ and $\beta=\left(\begin{array}{ll}1 & -1\end{array}\right)^{\prime}$, we then have

$$
\varphi_{t}=\operatorname{det}(B(1))^{-1}\left[\begin{array}{ll}
-\alpha_{2} & \alpha_{1}
\end{array}\right] \varepsilon_{t}
$$

For $\psi_{t}$, we follow Mellander, et al. (1992) and obtain

$$
\psi_{t}=\left(\alpha^{\prime} \Omega^{-1} \alpha\right)^{-1 / 2} \alpha^{\prime} \Omega^{-1} \varepsilon_{t}
$$




\section{Appendix B: Data sources}

Consumer price index. IMF's International Financial Statistics (IFS) CD-ROM

Nominal exchange rate. IFS CD-ROM.

Industrial production. OECD Main Economic Indicators.

Japan, the UK and the US: Industrial production, manufacturing.

Germany: Total industrial production.

Employment. OECD Main Economic Indicators.

Germany, Japan and the US: Employment in manufacturing.

UK: Quarterly data on total employment interpolated to monthly data.

Money stock.

Germany, Japan and the US: M1 taken from IFS CD-ROM

UK: M2 from Bank of England.

Long-term interest rate. OECD Main Economic Indicators.

Germany: 7-15 year public sector bonds.

Japan: 10-year benchmark central government bonds.

UK: 10-year government bonds.

US: Government bonds over 10 years. 


\section{References}

Alvarez, F. and A. Atkeson, 1997, Money and exchange rates in the Grossman-Weiss-Rotemberg model, Journal of Monetary Economics 40, 619-640.

Angell, J.W., 1926, The theory of international prices (Harvard University Press, Cambridge, MA).

Beaudry, P. and M.B. Devereux, 1995, Money and the real exchange rate with sticky prices and increasing returns, Carnegie-Rochester Conference Series on Public Policy 43, 55-101.

Bergin, P.R. and R.C. Feenstra, 1999, Pricing to market, staggered contracts, and real exchange rate persistence, National Bureau of Economic Research Working Paper No. 7026.

Bergman, M., 1996, International evidence on the sources of macroeconomic fluctuations, European Economic Review 40, 1237-1258.

Campbell, J.Y. and R.J. Shiller, 1988, Interpretating cointegrated models, Journal of Economic Dynamics and Control 12, 505-522.

Canzoneri, M.B., R.E. Cumby and B. Diba, 1999, Relative labor productivity and the real exchange rate in the long run: Evidence for a panel of OECD countries, Journal of International Economics 47, 245-266.

Cassel, G., 1916, The present situation of the foreign exchanges, Economic Journal 26, 62-65.

Cassel, G., 1921, The world's monetary problems (E.P. Dutton \& Company, New York).

Cassel, G., 1922, Money and foreign exchange after 1914 (Macmillan, London).

Cheung, Y.W. and K.S. Lai, 1998, Parity reversion in real exchange rates during the post-Bretton Woods period, Journal of International Money and Finance 17, 597-614.

Chari, V.V, P.J. Kehoe and E.R. McGrattan, 1998, Can sticky price models generate volatile and persistent real exchange rates, Federal Reserve Bank of Minneapolis Staff Report 223.

Clarida, R. and J. Gali, 1994, Sources of real exchange rate fluctuations: How important are nominal shock?, Carnegie-Rochester Conference Series on Public Policy 41, 1-56.

Culver S.E. and D.H. Papell, 1999, Long-run purchasing power parity with short-run data: Evidence with a null hypothesis of stationarity, Journal of International Money and Finance 18, 751-768.

Dornbusch, R., 1976, Expectations and exchange rate dynamics, Journal of Political Economy 84, 1161-1176.

Eichenbaum, M. and C.L. Evans, 1995, Some empirical evidence on the effects of shocks to monetary 
policy on exchange rates, Quarterly Journal of Economics 110, 975-1009.

Engel, C., 2000, Long-run PPP may not hold after all, Journal of International Economics, forthcoming.

Engel, C. and C-.J. Kim, 1999, The long-run U.S./U.K. real exchange rate, Journal of Money, Credit, and Banking 31, 335-356.

Evans, M.D.D. and J.R. Lothian, 1993, The responses of exchange rates to permanent and transitory shocks under floating exchange rates, Journal of International Money and Finance 12, 563-586.

Frankel, J.A. and A.K. Rose, 1996, A panel project on purchasing power parity: Mean reversion within and between countries, Journal of International Economics 40, 209-224.

Frenkel, J.A., 1978, Purchasing power parity: Doctrinal perspective and evidence from the 1920s, Journal of International Economics 8, 169-191.

Froot, K.A. and K. Rogoff, 1995, Perspectives on PPP and long-run real exchange rates, in: G. Grossman and K. Rogoff, eds., Handbook of international economics, Vol. 3 (North-Holland, New York) 1647-1688.

Harberler, G., 1936, The theory of international trade (W. Hodge \& Company, London).

Johansen, S., 1995, Likelihood-based inference in cointegrated vector autoregressive models (Oxford, Oxford University Press).

King, R.G., C.I. Plosser, J.H. Stock and M.W. Watson, 1991, Stochastic trends and economic fluctuations, American Economic Review 81, 819-840.

Kuo, B-.S. and A. Mikkola, 1999, Re-examining long-run purchasing power parity, Journal of International Money and Finance 18, 251-266.

Lothian, J.R., 1997, Multi-country evidence on the behavior of purchasing power parity under the current float, Journal of International Money and Finance 16, 19-35.

Lothian, J.R. and M.P. Taylor, 1996, Real exchange rate behavior: The recent float from the perspective of the past two centuries, Journal of Political Economy 104, 488-509.

Lütkepohl, H. and H.E. Reimers, 1992, Impulse response analysis of cointegrated systems, Journal of Economic and Dynamic Controls 16, 53-78.

Mellander, E., A. Vredin, and A. Warne, 1992, Stochastic trends and economic fluctuations in a small open economy, Journal of Applied Econometrics 7, 369-94.

Niehans, J., 1984, International monetary economics (Johns Hopkins University Press, Baltimore).

Obstfeld, M. and K. Rogoff, Exchange rate dynamics redux, Journal of Political Economy 103, 624-660. 
Oh, K.-Y., 1996, Purchasing power parity and unit root tests using panel data, Journal of International Money and Finance 15, 405-418.

Papell, D.H., 1997, Searching for stationarity: Purchasing power parity under the current float, Journal of International Economics 43, 313-332.

Pesaran, M.H. and Y. Shin, 1998, Generalized impulse response analysis in linear multivariate models, Economics Letters 58, 17-29.

Ricardo, D., 1811, The high price of bullion, in: E.C. Gonner, ed., Economic essays by David Ricardo, (Kelley, New York) 1966.

Ricardo, D., 1821, Principles of political economy and taxation, in: E.C. Gonner, ed. (Dent \& Sons, Ltd., London), 1912.

Rogers, J.H., 1999, Monetary shocks and real exchange rates, Journal of International Economics 49, 269-288.

Rogoff, K., 1996, The purchasing power parity puzzle, Journal of Economic Literature 34, 647-668.

Stock, J.H. and M.W. Watson, 1988, Testing for common trends, Journal of the American Statistical Association 83, 1097-1107.

Taylor, M.P. and L. Sarno, 1998, The behavior of real exchange rates during the post-Bretton Woods period, Journal of International Economics 46, 281-312.

Wheatley, J., 1803, Remarks on currency and commerce (Burton, London).

Wheatley, J., 1807, An essay on the theory of money and principles of commerce (Burton, London).

Wu, Y., 1996, Are real exchange rates nonstationary? Evidence from a panel-data test, Journal of Money, Credit, and Banking 28, 54-63. 
Table 1 Summary of cointegration analysis of error-correction coefficients

\begin{tabular}{lccc}
\hline Coefficient & Germany & Japan & U.K. \\
\hline$\alpha_{1}$ & -0.018 & -0.008 & -0.021 \\
& $(-1.966)^{* *}$ & $(-1.115)$ & $(-2.099)^{* *}$ \\
$\alpha_{2}$ & 0.002 & 0.005 & 0.005 \\
& $(1.881)^{*}$ & $(2.909)^{* * *}$ & $(1.968)^{* *}$ \\
Wald test for & & & $7.560^{* *}$ \\
$\left|\alpha_{1}\right|+\left|\alpha_{2}\right|=0$ & $7.167^{* *}$ & $9.426^{* * *}$ & 0.023 \\
p-value & 0.028 & 0.009 & \\
\hline
\end{tabular}

Notes: $\alpha=\left(\begin{array}{ll}\alpha_{1} & \alpha_{2}\end{array}\right)^{\prime}$ is the coefficient vector associated with the error correction term in the VEC model in equation (9). The parentheses underneath individual coefficient estimates give the corresponding $t$-statistics. Statistical significance is indicated by a single asterisk $\left({ }^{*}\right)$ for the 10 percent level, a double asterisk $\left({ }^{* *}\right)$ for the 5 percent level and a triple asterisk $\left({ }^{* * *}\right)$ for the 1 percent level. 
Table 2 Variance decomposition (in percentage) of the nominal exchange rate with respect to different innovations

\begin{tabular}{|c|c|c|c|c|c|c|}
\hline \multirow[b]{2}{*}{ Horizon } & \multicolumn{3}{|c|}{ Common-trend innovations } & \multicolumn{3}{|c|}{ Transitory innovations } \\
\hline & $\mathrm{DM}$ & JY & $\mathrm{BP}$ & $\mathrm{DM}$ & JY & $\mathrm{BP}$ \\
\hline 3 & 48.42 & 86.54 & 56.63 & 51.58 & 13.46 & 43.37 \\
\hline 6 & 53.75 & 85.94 & 57.97 & 46.25 & 14.06 & 42.03 \\
\hline 12 & 57.84 & 85.91 & 59.91 & 42.16 & 14.09 & 40.09 \\
\hline 24 & 61.23 & 86.57 & 63.17 & 38.77 & 13.43 & 36.83 \\
\hline 36 & 63.41 & 87.30 & 65.92 & 36.59 & 12.70 & 34.08 \\
\hline 48 & 65.13 & 87.97 & 68.23 & 34.87 & 12.03 & 31.77 \\
\hline 60 & 66.55 & 88.58 & 70.17 & 33.45 & 11.42 & 29.83 \\
\hline 72 & 67.74 & 89.11 & 71.81 & 32.26 & 10.89 & 28.19 \\
\hline 96 & 69.66 & 90.01 & 74.43 & 30.34 & 9.99 & 25.57 \\
\hline 120 & 71.15 & 90.71 & 76.46 & 28.85 & 9.29 & 23.54 \\
\hline
\end{tabular}

Table 3 Variance decomposition (in percentage) of the relative price with respect to different innovations

\begin{tabular}{|c|c|c|c|c|c|c|}
\hline \multirow[b]{2}{*}{ Horizon } & \multicolumn{3}{|c|}{ Common-trend innovations } & \multicolumn{3}{|c|}{ Transitory innovations } \\
\hline & $\overline{\text { Germany }}$ & Japan & U.K. & $\overline{\text { Germany }}$ & Japan & U.K. \\
\hline 3 & 64.38 & 13.59 & 43.28 & 35.62 & 86.41 & 56.72 \\
\hline 6 & 67.56 & 19.15 & 47.98 & 32.44 & 80.85 & 52.02 \\
\hline 12 & 73.07 & 27.39 & 55.56 & 26.93 & 72.61 & 44.44 \\
\hline 24 & 80.92 & 43.65 & 67.56 & 19.08 & 56.35 & 32.44 \\
\hline 36 & 86.00 & 57.23 & 75.87 & 14.00 & 42.77 & 24.13 \\
\hline 48 & 89.34 & 67.40 & 81.49 & 10.66 & 32.60 & 18.51 \\
\hline 60 & 91.59 & 74.73 & 85.33 & 8.41 & 25.27 & 14.67 \\
\hline 72 & 93.17 & 79.98 & 88.02 & 6.83 & 20.02 & 11.98 \\
\hline 96 & 95.14 & 86.57 & 91.40 & 4.86 & 13.43 & 8.60 \\
\hline 120 & 96.27 & 90.28 & 93.37 & 3.73 & 9.72 & 6.63 \\
\hline
\end{tabular}


Table 4 Variance decomposition (in percentage) of the real exchange rate with respect to different innovations

\begin{tabular}{|c|c|c|c|c|c|c|}
\hline \multirow[b]{2}{*}{ Horizon } & \multicolumn{3}{|c|}{ Common-trend innovations } & \multicolumn{3}{|c|}{ Transitory innovations } \\
\hline & $\mathrm{DM}$ & JY & $\mathrm{BP}$ & $\mathrm{DM}$ & JY & $\mathrm{BP}$ \\
\hline 3 & 34.52 & 70.81 & 32.93 & 65.48 & 29.19 & 67.07 \\
\hline 6 & 38.26 & 70.99 & 32.79 & 61.74 & 29.01 & 67.21 \\
\hline 12 & 40.74 & 71.06 & 32.64 & 59.26 & 28.94 & 67.36 \\
\hline 24 & 41.89 & 71.09 & 32.57 & 58.11 & 28.91 & 67.43 \\
\hline 36 & 42.21 & 71.09 & 32.56 & 57.79 & 28.91 & 67.44 \\
\hline 48 & 42.33 & 71.10 & 32.55 & 57.67 & 28.90 & 67.45 \\
\hline 60 & 42.39 & 71.10 & 32.55 & 57.61 & 28.90 & 67.45 \\
\hline 72 & 42.42 & 71.10 & 32.55 & 57.58 & 28.90 & 67.45 \\
\hline 96 & 42.44 & 71.10 & 32.55 & 57.56 & 28.90 & 67.45 \\
\hline 120 & 42.44 & 71.10 & 32.55 & 57.56 & 28.90 & 67.45 \\
\hline
\end{tabular}


Table 5 Causality tests for the macroeconomic sources of the common-trend and transitory innovations

\begin{tabular}{lllllcc}
\hline & \multicolumn{3}{c}{ Common-trend innovations } & & \multicolumn{3}{c}{ Transitory innovations } \\
\cline { 2 - 5 } Variable & Germany & Japan & U.K. & Germany & Japan \\
\hline$P R$ & $0.054^{*}$ & $0.008^{* * *}$ & 0.622 & 0.263 & 0.388 & 0.801 \\
$M S$ & $0.007^{* *}$ & $0.004^{* * *}$ & 0.627 & $0.073^{*}$ & $0.024^{* *}$ & 0.306 \\
$I R$ & 0.526 & 0.854 & 0.605 & $0.018^{* *}$ & $0.054^{*}$ & $0.091^{*}$ \\
$P R, M S$ and $I R$ & $0.003^{* *}$ & $0.012^{*}$ & 0.719 & $0.000^{* * *}$ & $0.017^{* *}$ & $0.058^{*}$ \\
$E C$ & $0.006^{* *}$ & 0.843 & $0.092^{*}$ & $0.000^{* * *}$ & $0.000^{* * *}$ & $0.000^{* * *}$ \\
\hline
\end{tabular}

Notes: The test results are based on estimation of the VEC model (equation (16)) with following variables: labor productivity differentials (PR), and relative money supply $(M S)$ and nominal interest rate differentials $(I R)$, and the error correction term $(E C)$. Robust standard errors are used in statistical analysis. The numbers in Table 5 are the p-values from standard Wald tests, which examine the null hypothesis of no causal effects (i.e., the hypothesis that all the corresponding coefficients associated with the relevant variable(s) are zero). Statistical significance is indicated by a single asterisk $\left({ }^{*}\right)$ for the 10 percent level, a double asterisk $\left({ }^{* *}\right)$ for the 5 percent level and a triple asterisk $\left({ }^{* * *}\right)$ for the 1 percent level. 
Table 6 Variance decomposition (in percentage) of individual innovations with respect to macroeconomic variables

\begin{tabular}{|c|c|c|c|c|c|c|c|c|c|}
\hline \multirow[b]{2}{*}{ Horizon } & \multicolumn{3}{|c|}{ Germany } & \multicolumn{3}{|c|}{ Japan } & \multicolumn{3}{|c|}{ U.K. } \\
\hline & $\overline{P R}$ & $M S$ & $\overline{I R}$ & $\overline{P R}$ & $M S$ & $\overline{I R}$ & $\overline{P R}$ & $M S$ & $\overline{I R}$ \\
\hline \multicolumn{10}{|c|}{ Common-trend innovations: } \\
\hline 3 & 0.79 & 2.26 & 1.12 & 5.17 & 0.22 & 0.43 & 0.80 & 0.76 & 0.39 \\
\hline 6 & 0.84 & 2.38 & 2.74 & 6.05 & 1.45 & 0.42 & 1.43 & 0.55 & 0.28 \\
\hline 12 & 1.31 & 2.12 & 4.35 & 5.27 & 4.11 & 0.71 & 2.32 & 0.30 & 0.15 \\
\hline 24 & 10.05 & 1.12 & 5.46 & 5.95 & 6.50 & 0.72 & 4.10 & 0.22 & 0.09 \\
\hline 36 & 20.96 & 1.54 & 5.76 & 9.72 & 7.16 & 0.56 & 5.95 & 0.19 & 0.11 \\
\hline 48 & 29.68 & 2.42 & 5.76 & 15.88 & 7.14 & 0.84 & 7.68 & 0.33 & 0.23 \\
\hline 60 & 35.98 & 3.28 & 5.67 & 23.85 & 6.70 & 1.74 & 9.17 & 0.56 & 0.38 \\
\hline 72 & 40.49 & 3.98 & 5.56 & 32.72 & 5.98 & 3.26 & 10.40 & 0.82 & 0.55 \\
\hline 96 & 46.22 & 5.00 & 5.39 & 49.20 & 4.25 & 7.35 & 12.26 & 1.28 & 0.83 \\
\hline 120 & 49.54 & 5.63 & 5.37 & 60.20 & 2.77 & 10.36 & 13.54 & 1.63 & 1.03 \\
\hline \multicolumn{10}{|c|}{ Transitory innovations: } \\
\hline 3 & 1.20 & 0.60 & 1.71 & 0.49 & 0.09 & 0.03 & 0.20 & 0.62 & 2.54 \\
\hline 6 & 2.40 & 0.46 & 5.62 & 1.15 & 4.98 & 0.99 & 0.20 & 0.67 & 2.35 \\
\hline 12 & 6.54 & 0.34 & 16.74 & 2.79 & 12.68 & 3.52 & 0.34 & 0.98 & 4.32 \\
\hline 24 & 12.62 & 0.68 & 35.07 & 5.30 & 22.89 & 12.15 & 0.70 & 6.49 & 18.18 \\
\hline 36 & 14.82 & 1.21 & 45.34 & 7.03 & 27.42 & 21.38 & 1.00 & 14.66 & 35.58 \\
\hline 48 & 15.47 & 1.72 & 51.42 & 8.18 & 29.28 & 28.89 & 1.12 & 20.36 & 46.48 \\
\hline 60 & 15.53 & 2.17 & 55.38 & 8.93 & 29.98 & 34.53 & 1.13 & 23.38 & 51.62 \\
\hline 72 & 15.38 & 2.56 & 58.14 & 9.46 & 30.20 & 38.69 & 1.11 & 24.88 & 53.82 \\
\hline 96 & 14.94 & 3.17 & 61.92 & 10.03 & 30.11 & 44.15 & 1.06 & 26.02 & 54.98 \\
\hline 120 & 14.54 & 3.61 & 63.90 & 10.35 & 29.90 & 47.40 & 1.02 & 26.34 & 54.94 \\
\hline
\end{tabular}

Note: The variables included are labor productivity differentials $(P R)$, and relative money supply $(M S)$ and interest rate differentials $(I R)$. 
Figure 1 The common-trend component versus the nominal exchange rate, the relative price and the real exchange rate.
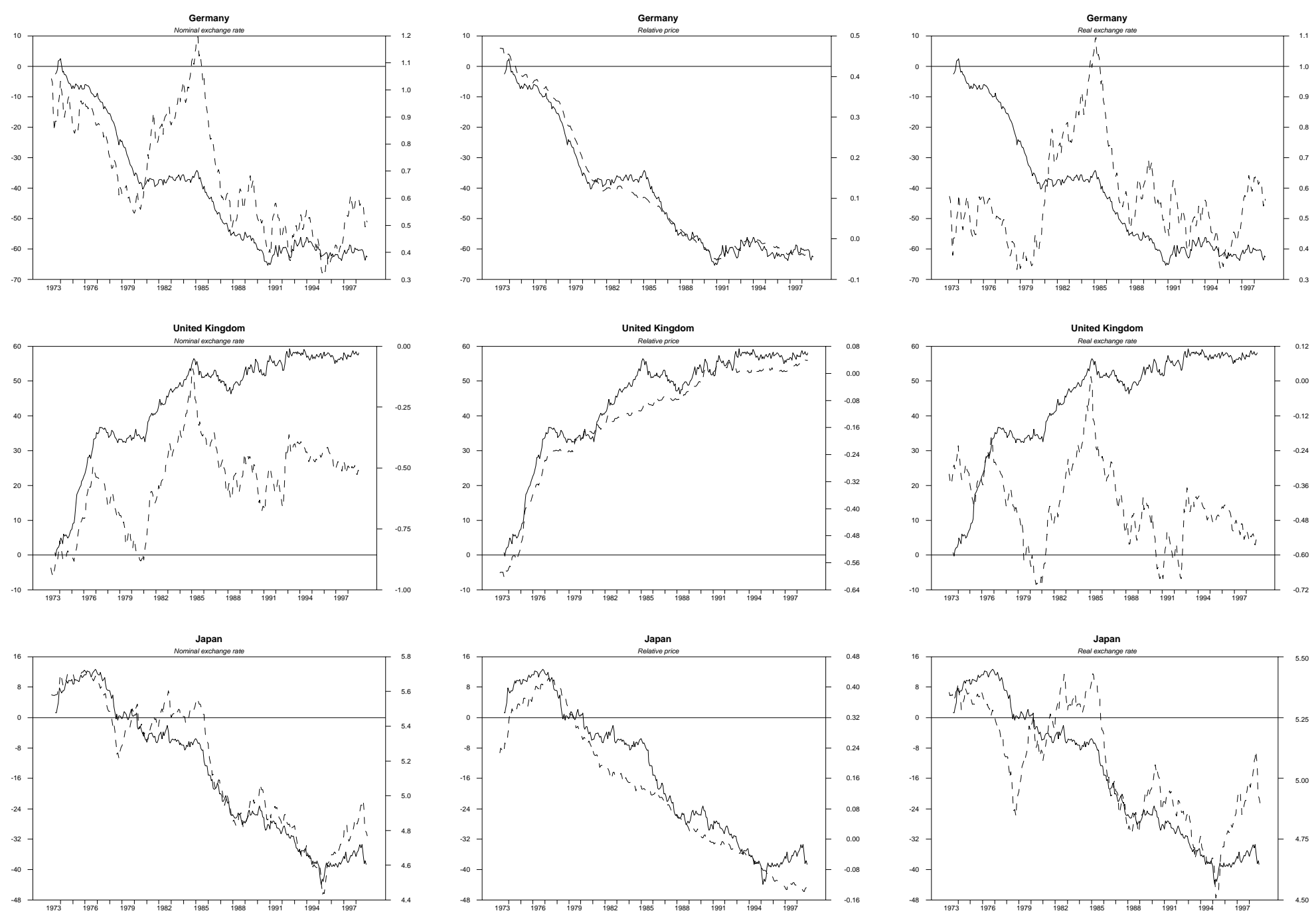
Figure 2 Impulse responses of the nominal exchange rate, the relative price and the real exchange rate to a one-standard-deviation innovation to the transitory component.
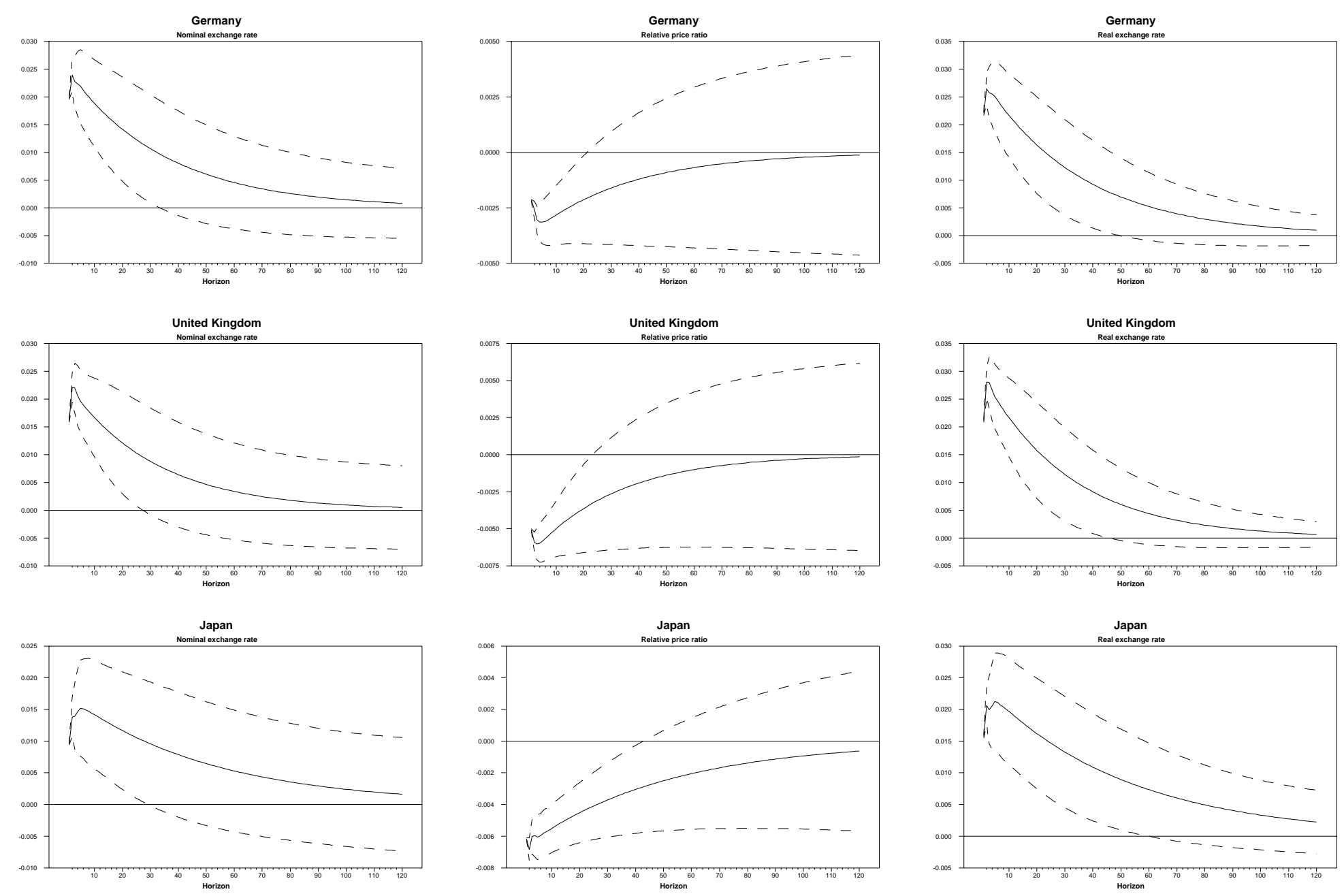
Figure 3 Impulse responses of the nominal exchange rate, the relative price and the real exchange rate to a one-standard-deviation innovation to the common-trend component.
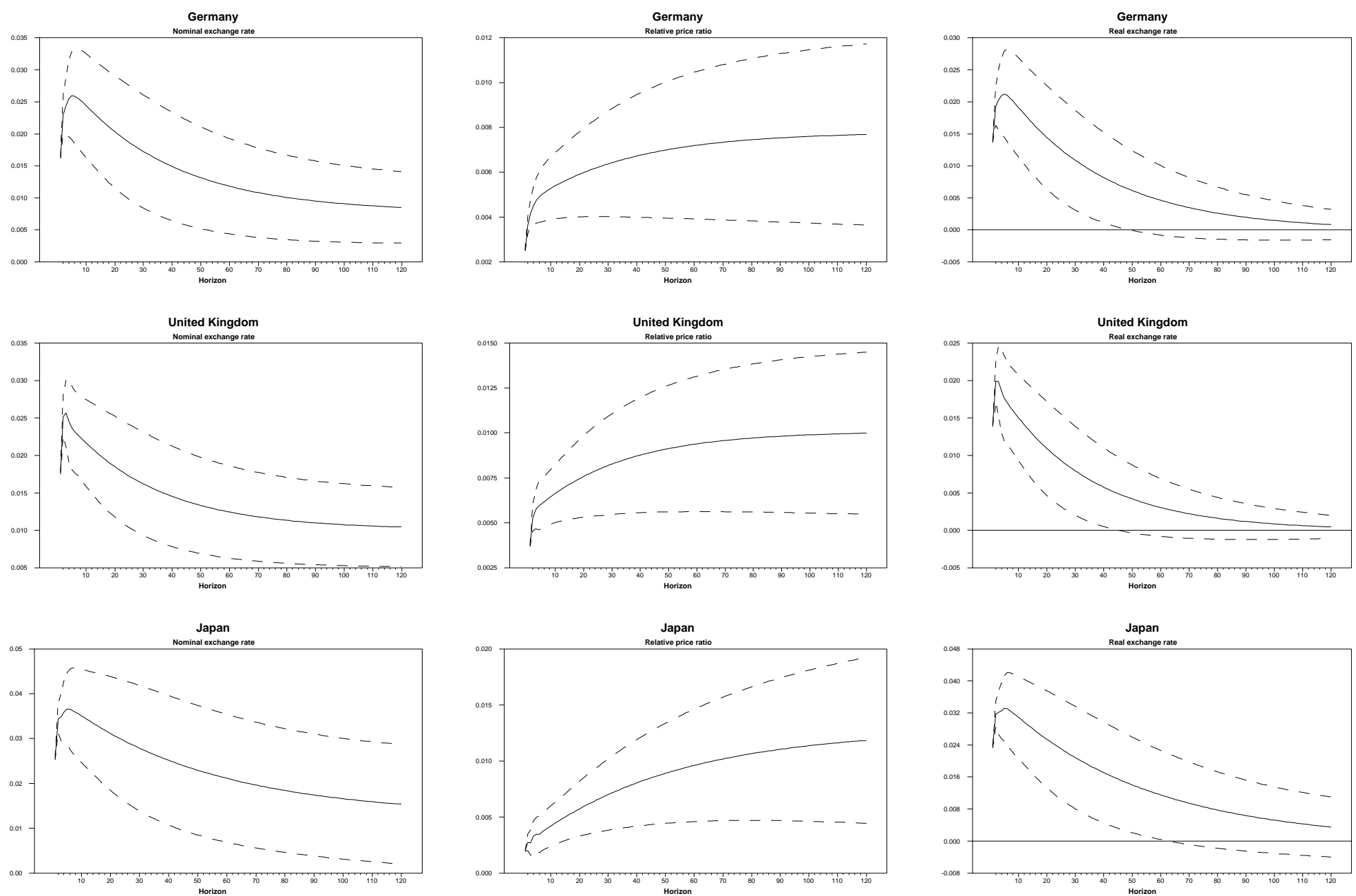
Figure 4 The proportion of forecast error variance of the nominal exchange rate, the relative price and the real exchange rate explained by transitory innovations.
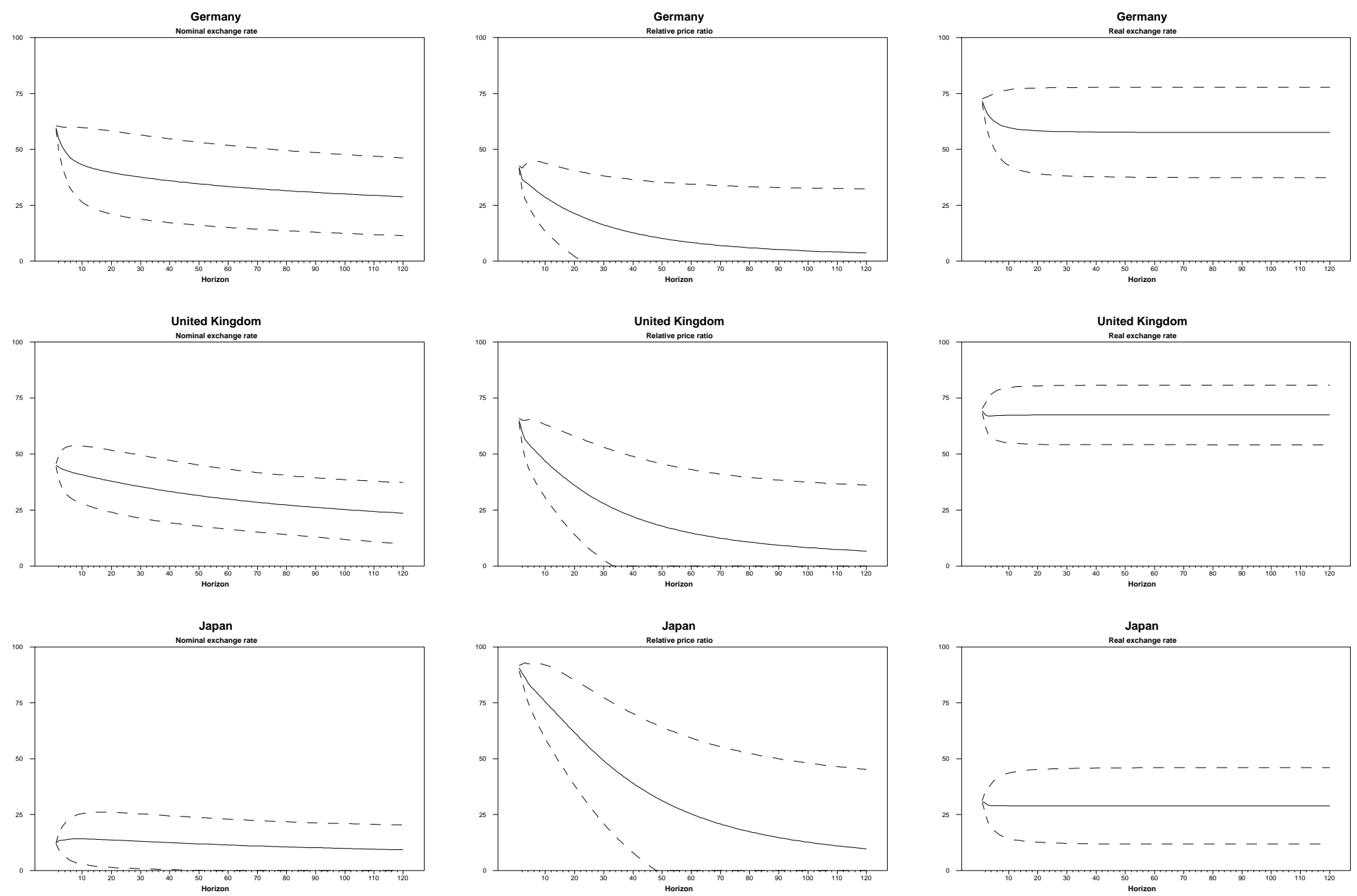
Figure 5 The proportion of forecast error variance of the nominal exchange rate, the relative price and the real exchange rate explained by common-trend innovations.
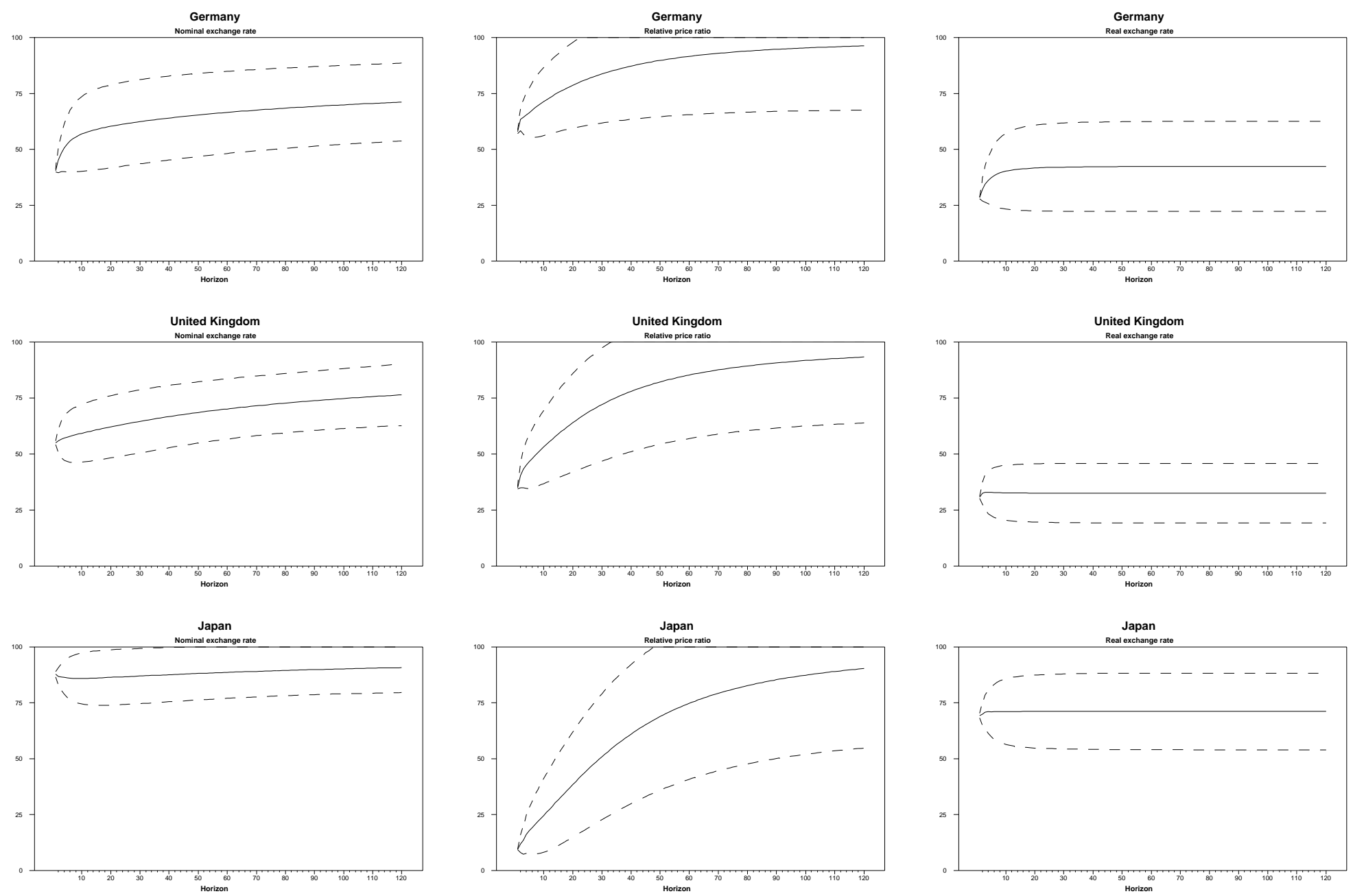